\title{
Tradução
}

\section{Tradução para dublagem de autor, controle autoral e de performance nas versões dubladas dos filmes de Stanley Kubrick ${ }^{1}$}

\author{
Auteur dubbing Translation, performance and authorial control in the \\ dubbed versions of Stanley Kubrick's films
}

Serenella ZANOTTI

Tradutores: Marileide Dias ESQUEDA*

Fernando Franqueiro GOMES ${ }^{* * *}$

\begin{abstract}
Stanley Kubrick was one of the few film directors who took an active role in the creation of foreign-language versions. From A Clockwork Orange onwards, he personally chose the dubbing director for all the dubbed versions and had an active part in the voice casting (CHIARO, 2007; NORNES, 2007). By looking at a variety of sources, this chapter aims to illustrate the genesis of the dubbed versions of Kubrick's films, focusing on the film director's role and degree of intervention in the production process. It will be argued that, by overseeing all aspects of the dubbing process, Kubrick conferred a special status on the foreign-language releases of his films, which are to be regarded as

RESUMO: Stanley Kubrick foi um dos poucos diretores de cinema que desempenhou um papel ativo na criação de versões fílmicas em língua estrangeira. Após a produção e direção de Laranja Mecânica, ele selecionou, pessoalmente, os diretores de dublagem para todas as versões dubladas e desempenhou um papel ativo na seleção do elenco de vozes (CHIARO, 2007; NORNES, 2007). Analisando uma variedade de fontes, este trabalho visa ilustrar a gênese das versões dubladas dos filmes de Kubrick, enfatizando o papel do diretor de cinema e seu nível de intervenção no processo de produção. Argumentar-se-á que, ao supervisionar todos os aspectos do processo de dublagem, Kubrick conferiu
\end{abstract}

\footnotetext{
${ }^{1}$ Traduzido sob autorização da John Benjamins Publishing Company.

* Professora Associada do Departamento de Língua Inglesa da Università degli Studi Roma Tre, Itália. ORCID: https://orcid.org/0000-0001-6622-7775. serenella.zanotti@uniroma3.it

${ }^{*}$ Doutora. Professora Associada do ILEEL/UFU e PPGEL/UFU. ORCID: https://orcid.org/0000-00026941-7926. marileide.esqueda@ufu.br

${ }^{* *}$ Doutorando PPLET/UFU. ORCID: https://orcid.org/0000-0001-6552-3134. fernandofranq@hotmail.com
} 
authorized versions on which an unusually evident authorial imprint was imposed.
PALAVRAS-CHAVE: Dubbing. Film Translation. Authorial Control. Stanley Kubrick. Archival Research. um status especial aos lançamentos em língua estrangeira de seus filmes, que devem ser considerados como versões autorizadas, às quais foi imposta uma marca autoral extraordinariamente inequívoca.

KEYWORDS: Dublagem. Tradução Fílmica. Controle Autoral. Stanley Kubrick. Pesquisa Arquivística.

\section{Apresentação da tradução}

Os Estudos da Tradução estabelecem, desde há muito, profícuas inter-relações com os Estudos Literários e Fílmicos, dando origem a diversas propostas de pesquisas interartes (DIAZ CINTAS, 2009; GAMBIER, 2003).

Nosso interesse, na qualidade de tradutores e pesquisadores em Estudos da Tradução, por estudos que preveem essas propostas de pesquisas, resultou, em 2014, em um trabalho intitulado "A tradução para o português dos palavrões em Os Infiltrados, de Martin Scorsese" (GOMES, 2014). Buscamos, nesse trabalho, discutir a forma como os palavrões presentes nos diálogos do filme Os Infiltrados, lançado em 2006, foram traduzidos para suas respectivas legendas em português. Observamos as estratégias tradutórias utilizadas nas legendas do filme por meio da taxonomia geral lançada por Yves Gambier (2003), a saber, omissão, equivalência e neutralização. Também levamos em consideração as discussões sobre o mercado de legendagem no Brasil e suas restrições relacionadas a palavrões a partir dos trabalhos de Diaz Cintas (2009), Esqueda (2012), Argentim e Esqueda (2012) e Esqueda et al. (2011). Refletimos, ainda, sobre a importância dos palavrões para o desenvolvimento da trama fílmica construída por Scorsese, desde a contextualização do ambiente até o desenvolvimento dos personagens.

O trabalho de adaptação de obras literárias para o cinema feito por Martin Scorsese também foi objeto de outras investigações nossas (GOMES, 2018). Estudamos 
o romance Ilha do Medo, de Dennis Lehane, e sua versão cinematográfica, de 2010. A pesquisa retratou o trabalho de adaptação de Scorsese, tendo como cerne a construção do personagem principal da narrativa, Edward "Teddy" Daniels, que além de protagonizar o romance e, consequentemente, o filme, é o elo entre todos os focos narrativos e visuais da produção. As noções de transcriação, de Haroldo de Campos (2010), e de tradução intersemiótica, de Julio Plaza (1997), somaram-se às nossas reflexões.

Atualmente, nosso olhar volta-se para outro importante diretor de cinema, Stanley Kubrick, por sua importância para a história do cinema e peculiar característica de controle de suas produções, principalmente quando exibidas em países de fala não inglesa. Os filmes O Iluminado, Laranja Mecânica e Nascido Para Matar, que são transcriações dos respectivos romances O Iluminado, de Stephen King, Laranja Mecânica, de Anthony Burgess e Nascido Para Matar, de Gustav Hasford, estão no foco de nossas análises atuais.

É sabido que Stanley Kubrick foi um diretor metódico e quase "obsessivo" com o seu trabalho, buscando sempre o máximo perfeccionismo em todos os aspectos de seus filmes, tanto que, na maioria deles, além de diretor, Kubrick também atuava como roteirista, produtor e até, em alguns casos, como editor e montador. O cineasta sempre fez questão de estar presente em vários momentos da pós-produção dos filmes e acompanhar o trabalho de outros profissionais, assegurando que tudo saísse conforme ele tinha planejado.

Recentemente, nos deparamos com o texto Auteur dubbing: translation, performance and authorial control in the dubbed versions of Stanley Kubrick's films (em tradução nossa: “Tradução para dublagem de autor, controle autoral e de performance nas versões dubladas dos filmes de Stanley Kubrick"), de autoria de Serenella Zanotti, publicado, em 2019, na obra Reassessing Dubbing: historical approaches and current trends 
(em tradução nossa: "Reavaliando a dublagem: abordagens históricas e tendências atuais"), da editora John Benjamins.

O texto, que respalda o que antes dissemos sobre o cuidado de Kubrick com seus filmes e o seu envolvimento nas diferentes fases das produções, evidencia, através de materiais e entrevistas, essa peculiar característica do diretor, que atuava diretamente nos processos de tradução, legendagem e dublagem de suas produções.

No texto que se segue, cujos direitos de tradução nos foram cedidos pela Editora John Benjamins, Serenella Zanotti observa que Stanley Kubrick chegava ao ponto, inclusive, de selecionar, ele mesmo, as equipes de tradutores, legendadores, diretores de dublagem e dubladores em vários países para os quais seus filmes seriam lançados, supervisionando cada etapa do processo.

O texto de Zanotti aponta que o principal motivo para Kubrick acompanhar o processo de tradução, legendagem e dublagem de seus filmes era o de fazer chegar ao espectador uma produção que não tivesse passado por alterações ou perdas de quaisquer natureza. Zanotti utiliza o termo auteur dubbing, que aqui adotamos, em nossa tradução para a língua portuguesa, "dublagem de autor", com a intenção de aludirmos às teorias de "cinema de autor", de François Truffaut (cf. nota de rodapé número 1 do artigo traduzido por nós).

Por fornecer importantes informações e noções, propomos, a seguir, a tradução do texto de Serenella Zanotti, que explica, de forma detalhada, a "dublagem de autor" de Stanley Kubrick.

Esperamos que a tradução que se segue não apenas beneficie os estudiosos dos Estudos da Tradução, dos Estudos Literários ou Fílmicos a melhor conhecerem o estilo de Kubrick, mas também a refletirem sobre o importante papel atribuído pelo cineasta à tradução audiovisual, em suas modalidades de tradução para produção de legendas e dublagens, que têm o potencial de levar as produções fílmicas a diferentes países e idiomas, de forma a engrandecê-las, dando origem a diálogos interartes. 


\section{Referências desta Apresentação}

ARGENTIM, J. P.; ESQUEDA, M. D. A tradução para o inglês de variantes dialetais em Lisbela e o Prisioneiro. Tradução \& Comunicação, n. 24, p. 95-110, 2012.

CAMPOS, H. de. A arte no horizonte do provável. São Paulo: Perspectiva, 2010.

DIAZ CINTAS, J. New trends in audiovisual translation. 1 ed. Bristol: Multilingual Matters, 2009. DOI https://doi.org/10.1057/9780230234581_1

GAMBIER, Y. Screen Transadaptation: Perception and Reception. The Translator. Studies in Intercultural communication. Manchester, v. 9, n. 2, p. 171-189, 2003. DOI https://doi.org/10.1080/13556509.2003.10799152

GOMES, F. F. A tradução para o português dos palavrões do filme Os Infiltrados, de Martin Scorsese. 2014. 45 f. Monografia (Bacharelado em Tradução) - Universidade Federal de Uberlândia.

GOMES, F. F. Dennis Lehane e Martin Scorsese: dois olhares sobre a construção da personagem Edward "Teddy" Daniels de Ilha do Medo. 2018. 132 f. Dissertação (Mestrado em Estudos Literários). Universidade Federal de Uberlândia, Uberlândia.

ESQUEDA, M. D. O filme “Tropa de Elite" em espanhol: a questão da tradução dos palavrões. Abehache. v. 2, n. 3, São Paulo, p. 145-161, 2012.

ESQUEDA, M. D. et al. A Grande Família - O filme e The Big Family - The film: a tradução no ensino comunicativo de línguas. Tradterm, v. 18, p. 265-296, 2011. DOI https://doi.org/10.11606/issn.2317-9511.tradterm.2011.36764

PLAZA, J. Tradução Intersemiótica. São Paulo: Perspectiva, 1987.

ZANOTTI, S. Auteur dubbing Translation, performance and authorial control in the dubbed versions of Stanley Kubrick's films. In: Reassessing Dubbing: historical approaches and current trends. Amsterdã: John Benjamins Publishing Company, 2019. p. 80-100. DOI https://doi.org/10.1075/btl.148.04zan 


\section{Tradução do texto:}

Auteur dubbing ${ }^{2}$. Translation, performance and authorial control in the dubbed versions of Stanley Kubrick's films, de autoria de Serenella Zanotti, publicado na obra Reassessing Dubbing: Historical approaches and current trends, organizada por Irene Ranzato e Serenella Zanotti, em 2019.

Editora: John Benjamins Publishing Company. Amsterdam/Philadelphia https://benjamins.com/catalog/btl.148

\section{Introdução ${ }^{3}$}

A reputação de Stanley Kubrick, como cineasta-autor, "totalmente refletida em seu trabalho" (CIMENT, 2001, p. 41), é com frequência associada à imagem do perfeccionista obsessivo "marcadamente presente em todas as etapas da produção cinematográfica" (McDOUGAL, 2003, p. 62). Entretanto, embora o compromisso do diretor em manter um "controle autocrático sobre um determinado trabalho" (CIMENT, 2001, p. 41) faça parte da lenda sobre Kubrick, seu envolvimento na produção das versões estrangeiras de seus filmes é raramente comentado por seus estudiosos, se é que alguma vez já o foi. Deve-se notar que esses dois aspectos do modus operandi artístico de Kubrick - seu perfeccionismo, por um lado, e, por outro, sua preocupação com o destino de seus filmes traduzidos - estão relacionados de forma interessante em vários artigos publicados na imprensa internacional ao longo dos anos. Quando escreveu para o Le Nouvel Observateur por ocasião do lançamento francês de Nascido Para Matar, em outubro de 1987, Alain Riou observou:

Todos conhecem o lendário Kubrick - um demônio de beleza, por assim dizer, da mesma forma que existem demônios do crime, que

\footnotetext{
2 Nota dos Tradutores: Auteur dubbing translation foi traduzido como "Tradução para dublagem de autor", levando-se em consideração as teorias de "cinema de autor", de François Truffaut.

${ }^{3}$ Eu gostaria de agradecer ao SK Film Archives LLC, à Warner Bros., à Universidade de Artes de Londres e aos doadores dos Arquivos Stanley Kubrick por me concederem a permissão de publicar trechos dos materiais não publicados. Eu também sou grata a Georgina Orgill e todos os membros da equipe do Arquivo Stanley Kubrick por sua ajuda e sugestões. Além disso, eu gostaria de agradecer a Filippo Ulivieri por compartilhar suas ideias e matérias sobre Stanley Kubrick e a dublagem.
} 
reina, escondido em um bunker secreto, sobre um exército de agentes que se movimentam em todo o mundo para garantir uma projeção de boa qualidade para seus filmes. Um perfeccionista, um maníaco que tende ao mínimo detalhe, e cujo último filme, finalmente entregue após sete anos de silêncio, empurra a precisão para as fronteiras da loucura. Tudo isso é verdadeiro e falso ao mesmo tempo. O certo é que o diretor de Laranja Mecânica procura controlar o máximo possível a distribuição de suas obras, cuidando delas como um pai cuida de seus filhos, a ponto de confiar aos diretores que são consagrados em seu próprio país a delicada tarefa de supervisionar as versões em língua estrangeira. (RIOU, 1987, p. 53-54, minha tradução)

Como diretor de cinema que exerceu controle sobre todos os aspectos da produção e pós-produção, Kubrick também desempenhou um papel determinante na distribuição de seus filmes no exterior e teve um papel ativo na tradução dos diálogos fílmicos. Nas palavras de Michel Ciment, "o cuidado extremo que ele [trouxe] ao lançamento de seus filmes simplesmente reflete sua preocupação em vê-los exibidos nas melhores condições possíveis, sem que sejam comprometidos por uma má impressão, projeção defeituosa ou dublagem rasa" (2001, p. 42), razão pela qual ele supervisionou pessoalmente todas as versões dubladas (CIMENT, 2001, p. 41). Como destacou o tradutor espanhol escolhido por Kubrick, Vicente Molina Foix, o envolvimento do diretor extrapolava o processo de produção, pois ele era muito ativo também nas fases de marketing e distribuição:

Não creio que o público em geral saiba que esse diretor, que tem uma merecida reputação como perfeccionista, agia dessa forma não apenas ao filmar e editar seus filmes, mas também no momento da preparação e distribuição. Kubrick estava no controle de todo o processo, às vezes impondo drasticamente sua vontade aos estúdios de Hollywood, e exigindo que seus filmes fossem lançados, em todos os países do mundo onde a dublagem é a norma, em versões que ele mesmo supervisionou além dos limites convencionais, desde a tradução até o diretor de dublagem e a voz de cada ator principal. (MOLINA FOIX, 1999, minha tradução) 
Todos os aspectos de seus filmes traduzidos "foram cuidadosa e pessoalmente supervisionados pelo diretor" (MOLINA FOIX, 2005, In: PÉREZ-GONZÁLEZ, 2014, p. 191). Kubrick prestava muita atenção “aos mínimos detalhes linguísticos” (MOLINA FOIX, 2005), fazendo com que os diálogos e legendas traduzidos fossem retraduzidos para o inglês ou cuidadosamente revisados por linguistas. Como observa McQuiston (2013, p. 8), “apesar da aparente desconfiança de Kubrick em relação aos idiomas de seus filmes, ele assegurou que suas versões em língua estrangeira não omitissem nada essencial", o que é "uma prova de sua preocupação com a clareza e o significado linguísticos", mas também um indício da importância que Kubrick atribuía à tradução de filmes como um fator crucial para garantir o sucesso internacional de bilheteria e perante à crítica.

A preocupação de Kubrick foi muito além de garantir que os roteiros de dublagem e legendagem representassem fielmente os diálogos originais - após a produção e direção de Laranja Mecânica, ele selecionou, pessoalmente, os diretores de dublagem para todas as versões dubladas e tomou decisões sobre o elenco de vozes. Segundo Molina Foix, Kubrick "realizava a gravação de diferentes vozes de dubladores enviadas para sua avaliação" e selecionava pessoalmente "uma voz específica para cada parte" (MOLINA FOIX, 2005, In: PÉREZ-GONZÁLEZ, 2014, p. 191). Seleções como essas não são incomuns quando se trata também de seus tradutores e colaboradores, e parecem ser bastante consistentes em evidenciar, de forma bastante clara, o envolvimento do diretor no processo de tradução dentro do contexto de seu perfeccionismo obsessivo. Embora o mito do diretor de cinema diligente e protetor de seu trabalho tenha sido questionado por um estudo recente, que tendeu a enfatizar a dimensão colaborativa do método de trabalho de Kubrick (McAVOY, 2015), não há dúvidas de que sua abordagem de tradução de filmes tenha sido bastante incomum. O objetivo deste texto é precisamente lançar alguma nova luz sobre esse aspecto subexplorado do trabalho do diretor de cinema. Ao olhar para uma 
variedade de documentos do Arquivo Stanley Kubrick, em Londres ${ }^{4}$, este trabalho procura ilustrar o que os materiais arquivados podem revelar sobre o papel e o nível de intervenção desse diretor no processo de dublagem, bem como seu método de trabalho quando se trata de versões em língua estrangeira.

Como tentarei ilustrar, embora o nível de envolvimento pessoal de Kubrick no processo de tradução varie de filme para filme, e de versão estrangeira para versão estrangeira, a maioria das versões dubladas de seus filmes podem ser consideradas como portadoras, em maior ou menor grau, de uma marca autoral.

\section{Stanley Kubrick e versões em idiomas estrangeiros}

Como observa Mark Betz (2009, p. 50),

O que depõe contra a dublagem é a falta de sincronismo labial e sonoro entre a voz e o corpo, precariedade das performances e do som e alteração ou eliminação da trilha sonora e do design do filme original. A qualidade da performance é frequentemente notada como sofrível nos filmes dublados, pois as qualidades vocais, tons e ritmos de idiomas específicos, combinados com os gestos e expressões faciais que marcam os personagens e estilos de performance nacionais, são perdidos na tradução. A maioria dos críticos de dublagem veem-na, portanto, como menos autêntica do que a legendagem, devido às alterações que ela provoca nas performances filmadas e à destruição que ela causa na trilha sonora do filme.

A fim de conceder acesso a seus filmes nas melhores condições possíveis, Kubrick cuidou minuciosamente de todos os aspectos do processo de dublagem, desde a tradução até o elenco de vozes e performance - um fato que aponta para sua consciência do poder da tradução de filmes sobre os efeitos de recepção. Não

\footnotetext{
${ }^{4} \mathrm{O}$ Arquivo encontra-se no Centro de Arquivos e Coleções Especiais da Universidade de Artes, em Londres (UAL).
} 
surpreendentemente, o "cuidado obsessivo" que ele dedicou às versões dubladas de seus filmes foi mote recorrente na imprensa francesa, na qual afirmações como "Stanley Kubrick teve cuidado alucinado com a dublagem de seus filmes" (minha tradução $)^{5}$ não foram incomuns. Em 1987, falando com a jornalista do Le Monde, Danièle Heymann, o diretor explicou o método que vinha aperfeiçoando ao longo dos anos para lidar com versões estrangeiras:

Você também acompanha de perto a dublagem e legendagem de seus filmes? Isso é verdade para a dublagem. Eu escolho bons diretores para todos os quatro idiomas envolvidos: espanhol, italiano, alemão e francês. Eu ouço os testes de vozes que eles propõem. Eu os deixo gravar a trilha sonora e depois a trazemos de volta aqui para mixá-las. A mixagem é crucial para obter certo equilíbrio no resultado final. O som gravado em estúdio é sempre muito rico, muito limpo, comparado ao som original, que foi gravado ao ar livre. Por isso, muitas vezes, temos de atenuar o som, cortar certas frequências, reduzir a qualidade para que pareça mais autêntica. (HEYMANN, 2005, p. 477)

Aqui Kubrick parece estar minimizando sua abordagem "intervencionista” em relação às versões estrangeiras, buscando transparecer que sua ação limita-se à escolha dos diretores de dublagem, elenco de vozes e mixagem de som. Localizada no Arquivo Stanley Kubrick está uma cópia original datilografada dessa entrevista, com sugestões de alterações e passagens eliminadas da escrita de Kubrick ${ }^{6}$. A entrevista, que foi publicada após a estreia de Nascido para Matar, abordou vários tópicos, incluindo a tradução. Algumas observações muito interessantes são encontradas em passagens que não foram incluídas na publicação final da entrevista. Por exemplo, quando Heymann pergunta a Kubrick se ele tinha ficado feliz com as versões dubladas que ele recebeu dos diretores franceses, ele diz: “Claro!”, na versão oficialmente publicada, ao

5 "Cannes 1999", La Croix, 20 de maio de 1999. (Disponível em: https://www.lacroix.com/Archives/1999-05-20/\%20Cannes-1999- NP -1999-05-20-475391. Acesso em: 3 nov. 2017). ${ }^{6} \mathrm{SK} / 1 / 2 / 8 / 5$. 
passo que ele pareceu muito menos entusiasmado na entrevista original: “Ah sim... eu estou satisfeito com as versões, com todas as versões dos meus filmes, nas quais estive envolvido [...] escolhendo o diretor e o tradutor [...]. E certificando-me de que havia recursos financeiros suficientes para contratar bons atores" (p. 47). Mas quando se trata da versão francesa de Nascido para Matar, Kubrick era bastante vago, já que a pessoa que tinha iniciado os trabalhos, ou seja, o diretor de cinema francês Henri Verneuil, foi substituído em um determinado momento durante a produção por outro diretor, Michel Deville, que tinha supervisionado a versão francesa de O Iluminado. Quando questionado sobre as versões dubladas em geral, Kubrick afirmou de forma bastante eloquente: "É como fazer outro filme" (p. 46), e depois passou a explicar todo o processo em pormenores. Na visão do diretor, "duas coisas [podem] dar errado com as versões estrangeiras: primeiramente os roteiros podem ser muito mal traduzidos, e, por consequência, mal interpretados". Ele argumentou que, uma vez que a tradição era que a mixagem fosse feita no país de destino, pessoas que não conheciam o filme manejavam todo o processo e, muito frequentemente, devido à pressão de tempo, trabalhavam de forma muito rápida, causando um enorme impacto no resultado final. Como consequência, a mixagem era, muitas vezes, feita de tal forma "que o diálogo permanecia em volume alto, e todo o resto ficava de fora" (p. 48). Depois de 2001: Uma Odisseia no Espaço a abordagem de Kubrick com relação às versões dubladas mudou, pois ele entendeu que uma maneira de fugir do problema era garantir que os mesmos profissionais de mixagem, que tinham mixado o filme em inglês, cuidassem também das versões estrangeiras.

Essa passagem da entrevista revela insights sem precedentes sobre a realização dos seus filmes dublados, mostrando o quão centralizadora, estruturada e cuidadosamente gerenciada era sua abordagem para trabalhar com as versões em idiomas estrangeiros. Nosso interesse aqui, em especial, é o reconhecimento de Kubrick de que ele devia a ideia de utilizar os mesmos profissionais de mixagem para 
mixar as versões em inglês e as versões estrangeiras dubladas à MGM, que ele considerava ser a única maneira de garantir a qualidade sonora em todas as versões. No entanto, a intervenção autoral do diretor foi muito além do campo da engenharia de som, deixando sua marca pessoal em todos os aspectos das versões dubladas de seus filmes.

\section{Dublagem de autor}

Como observa Abé Mark Nornes (2007, p. 14), os cineastas relutam em se envolver na tradução e preferem deixar para os distribuidores a tarefa de cuidar da transferência linguística:

[...] a maioria dos roteiristas e diretores nunca participa da tradução de seus trabalhos. Os produtores do filme assumem a responsabilidade pela supervisão, quando ela acontece. Na maioria das traduções, os distribuidores (que geralmente veem filmes e televisão mais como produto do que como arte) e seus tradutores assumem total controle e geralmente cortam, censuram e revisam o texto original para atender aos caprichos e costumes culturais locais.

Isso é precisamente o que Kubrick tentou evitar, pois foi um dos poucos diretores de cinema que entendeu a tradução de filmes "como parte integrante do processo da criação artística de um filme e não como um mero apêndice sujeito às forças do mercado" (DIAZ CINTAS, 2001, p. 207). Steve Southgate, que estava encarregado das operações técnicas europeias para a Warner Brothers e trabalhou em todos os filmes de Kubrick a partir de Laranja Mecânica, lembrou a preocupação do diretor e seu envolvimento pessoal com a distribuição de seus filmes no exterior:

Ele pertencia à indústria cinematográfica e sabia como era seu funcionamento, inclusive em todos os países do mundo. Ele conhecia todas as pessoas que dublavam, os diretores de dublagem, os atores, ele tinha relações com diretores estrangeiros que supervisionavam seu trabalho, já que ele não podia estar lá para supervisionar por si mesmo. 
Tivemos que ir a todos os cinemas para garantir que as luzes de projeção estivessem corretas, que o som estivesse correto, que as proporções estivessem corretas, que as telas estivessem limpas. (In: BOGDANOVICH, 1999, grifos meus)

Em países como França, Itália, Alemanha e Espanha, que comumente dublam filmes importados, o surgimento de uma sólida indústria de dublagem, com estúdios especializados que empregam um pequeno corpo de profissionais altamente especializados, levou ao desenvolvimento de um conjunto de práticas e convenções altamente padronizadas. Foi especificamente para escapar das rotinas e deficiências da dublagem industrial que "com o tempo diretores, como Stanley Kubrick e Steven Spielberg, escolheram trabalhar com diretores de dublagem escolhidos a dedo" (MIRA, 2010, p. 106), ou decidiram se envolver pessoalmente na criação de uma versão em língua estrangeira, como foi o caso da versão em DVD de O Tigre e o Dragão, de Ang Lee, supervisionada diretamente tanto pelo diretor quanto pelo roteirista (NORNES, 2007, p. 14). Como Alberto Mira (2010, p. 106) aponta, “tal dublagem de autor tem seus próprios problemas, pois parece ser uma condição central da dublagem que ela seja 'invisível', e o público rejeitará veementemente a dublagem que chama a atenção para si mesma". Esse foi o caso da versão espanhola dublada de O Iluminado.

Molina Foix explica que Kubrick estava muito preocupado com as versões em espanhol de seus filmes, para as quais ele selecionou pessoalmente diretores de cinema que ele admirava:

Kubrick, cuja filha conhecia bem o espanhol e lhe deu vários conselhos, teve um cuidado especial com a versão espanhola de seus filmes. Carlos Saura, Jaime de Armiñán, Mario Camus (ele também pensou em Víctor Erice, que não estava disponível naquela época) são os diretores espanhóis que Kubrick escolheu, por admirar seus trabalhos, para a supervisão das versões em espanhol, evitando as ações corriqueiras dos estúdios de dublagem. Eles podem testemunhar o quanto ele era exigente, às vezes de forma obsessiva. (MOLINA FOIX, 1999, minha tradução) 
Kubrick não queria que as versões dubladas soassem como filmes dublados, portanto ele insistiu em contratar diretores de dublagem que fossem diretores de cinema e em associar-se a tradutores nos quais pudesse confiar.

Como destaca Molina Foix (2005), ele adotou a mesma abordagem para todos os seus filmes, "cuidando com muito carinho" de todos os aspectos, desde a qualidade de produção até a tradução, exigindo "fidelidade escrupulosa ao diálogo original" (minha tradução) e uma abordagem diferente daquela da dublagem comum. As versões em espanhol foram direta e constantemente supervisionadas pelo diretor de cinema, que prestou atenção às minúcias, tanto na tradução quanto nas performances dos atores-dubladores": "todos eles foram direta e constantemente supervisionados por Kubrick em seus mínimos detalhes linguísticos ou vocais (o diretor recebeu os testes de vozes dos diferentes atores para cada um dos papéis do filme, e os escolheu ele mesmo)" (MOLINA FOIX, 2005, minha tradução). Dado o envolvimento de Kubrick no processo, as versões dubladas de seus filmes podem ser descritas como tendo a marca do cineasta. Portanto, proponho o termo auteur dubbing ${ }^{8}$ (dublagem de autor) para descrever uma abordagem de dublagem que incorpora a visão do diretor do filme como um efeito da colaboração do tradutor com o artista 9 .

\footnotetext{
${ }^{7}$ Nota dos Tradutores: o termo em inglês dubbing actors ("atores-dubladores" ou simplesmente "atores") é por vezes utilizado no texto em contraposição ao termo dubbers (dubladores). Serenella Zanotti referese a dubbing actors como os profissionais que eram contratados para as dublagens dos filmes de Kubrick, mas que não necessariamente pertenciam à indústria de dublagem, neste caso, os dubbers. Segundo a autora, Kubrick preferia contratar atores para dublarem seus filmes, em vez de dubladores pertencentes à indústria. Ver seção 3.5 a seguir.

${ }_{8}$ Minha definição de "dublagem de autor" é derivada da definição de "descrição de autor", de Szarkowska, uma abordagem que "incorpora a visão criativa do autor no roteiro [...] e, portanto, fornece ao descritor de áudio a licença artística para se afastar do ditame do objetivismo" (2013, p. 383). Ver Hodson (2017) para uma discussão sobre conceitos de autoria.

${ }_{9}^{9}$ Assim como nos é lembrado por Nornes (2007, p. 221), no caso da dublagem, "o tradutor deve fazer parte da 'equipe de técnicos, tradutores e atores', em vez de ser considerado um profissional isolado, enquanto todo o trabalho de dublagem é realizado por múltiplos colaboradores".
} 


\subsection{Filmagens que têm em mente as versões em línguas estrangeiras}

A preocupação de Kubrick em garantir o envolvimento do espectador nas versões em língua estrangeira de seus filmes é epitomizada na famosa cena do manuscrito de Jack em O Iluminado. Este é um momento-chave do filme que marca o início da inclinação de Jack à loucura. Sua esposa Wendy descobre que ele só digita a mesma frase há semanas ("All work and no play makes Jack a dull boy" / "Muito siso e pouco riso fazem de Jack um infeliz"), um sintoma de sua crescente alienação. Kubrick entendeu que essa cena caracterizava-se como uma reviravolta no filme, e que, portanto, não teria impacto se traduzida em legendas, e por isso foram inseridas filmagens com diferentes versões da cena com a frase traduzida e dublada para quatro idiomas (ver HOOTON, 2015). Várias pilhas de papéis datilografados contendo as versões em francês, alemão, italiano e espanhol das páginas que aparecem na tela como folhas de Wendy do manuscrito de Jack estão, de fato, armazenadas no Arquivo Stanley Kubrick (SK/15/3/4/2). Curiosamente, não apenas o leiaute visual das páginas muda em cada versão, mas também diferentes associações são desencadeadas em cada tradução, pois o objetivo é transmitir o estado de espírito de Jack e não o significado do provérbio.

O uso de filmagens inseridas em múltiplos idiomas não é exclusivo dos filmes de Kubrick (ver O'SULLIVAN, 2013), mas alia-se à preocupação do diretor com o destino de seu trabalho na tradução e, talvez, mais importante do que isso, à sua compreensão do efeito ilusionista da dublagem como técnica que contribui para o efeito ilusionista do cinema. Refletindo sobre a qualidade hipnótica do filme, Kubrick afirmou certa vez:

Acho que um público que assiste a um filme ou a uma peça de teatro está em um estado muito semelhante ao de sonhar, e que a experiência da dramaturgia torna-se uma espécie de sonho controlado [...]. Mas o ponto importante aqui é que o filme se comunique em um nível subconsciente, e o público responda ao formato básico da história em 
um nível subconsciente, como responde a um sonho. (In: WEINRAUB, 1972, p. 26)

Ele estava ciente do impacto que a tradução, e a dublagem em especial, têm na recepção dos filmes e da forma como elas contribuem para a criação da ilusão cinematográfica, portanto, prestou especial atenção à natureza material do processo de representação por trás dessa ilusão e decidiu se envolver diretamente no processo de tradução.

\subsection{Escolha do diretor de dublagem}

A principal tarefa do diretor de dublagem é orientar o trabalho interpretativo dos dubladores:

Assim como o diretor de uma peça de teatro ou filme, o diretor de dublagem é responsável por incitar, estimular e instruir os dubladores para que realizem suas melhores performances. Ele pode exigir que as falas sejam lidas de maneira diferente, redirecionando a ênfase e mudando a expressão. Sugestões e críticas relativas à entonação, expressão e projeção da voz também são feitas pelo diretor. Antes de cada tomada, o diretor pode acrescentar uma observação ou dois esboços para as cenas que estão sem os devidos contextos, com vistas a ajudar o dublador: onde está o personagem, o que o personagem sente, qual a mensagem que se pretende transmitir. (WHITMANLINSEN, 1992, p. 82)

Os diretores de dublagem com quem Kubrick escolheu trabalhar foram selecionados, na maioria dos casos, em virtude de serem externos à indústria da dublagem local e também muito bons na direção dos atores. Por exemplo, Kubrick alegou ter abordado o diretor espanhol Carlos Saura para supervisionar a versão espanhola de Laranja Mecânica, não só porque ele o achava “um diretor extremamente brilhante", mas especialmente pela "forma maravilhosa como coordenava seus atores" (ver MOLINA FOIX, 1980). 
Ao lembrar como se tornou a diretora da dublagem francesa de De olhos bem fechados, a cineasta Pascale Ferran observou que, embora a grande maioria das dublagens fosse dirigida por profissionais da área, em se tratando de diretores de cinema como Kubrick e Fellini, esse dificilmente era o caso:

A grande maioria dos filmes dublados é dirigida por diretores de dublagem profissionais. Kubrick e Fellini são exceções bem conhecidas, pois ambos estavam muito atentos às dublagens de seus filmes, para as quais eles geralmente escolhiam diretores de cinema. [...] Para Kubrick, a linha de conduta era clara: na maioria das vezes, ele escolhia trabalhar com diretores de cinema, exceto nos países onde trabalhava com um diretor de dublagem de confiança, como era o caso na Itália. Este também era o caso na França, oferecendo, inclusive, a dublagem de O Iluminado a Michel Deville. Para De olhos bem fechados, a versão espanhola foi dirigida por Carlos Saura e a versão alemã por Edgar Reitz, diretor de Heimat. (In: MILLON E RENOUARD, 1999, minha tradução)

A prática de contratar diretores de cinema para supervisionar a dublagem em língua estrangeira não era exclusiva de Stanley Kubrick. Como sugerido por Renouard (1999, p. 47),

Dentre os cineastas franceses que serviram os estrangeiros, podemos citar Louis Malle, que supervisionou a versão francesa de $O$ poderoso Chefão, de Coppola; Alain Resnais, que trabalhou no Quinteto, de Altman; Michel Deville, que foi contratado duas vezes por Stanley Kubrick (para O Iluminado, em 1979, e Nascido para matar, em 1987); Patrice Chéreau, que dublou Casanova, de Fellini, em 1976. [...] Por sua vez, os distribuidores franceses parecem ter entendido a importância da dublagem em mercados estrangeiros como os dos Estados Unidos; como consequência, Mel Brooks foi convidado a supervisionar a versão americana de Os visitantes. (minha tradução)

Kubrick escreveu a Carlos Saura, em 1971, reclamando que sempre teve dificuldades para que seus filmes fossem dublados com sucesso. Ele expressou sua admiração pelo trabalho de Saura e pediu-lhe para dirigir a versão espanhola de 
Laranja Mecânica, afirmando que não estava inclinado a contratar um profissional do mundo da dublagem. Ele também pediu conselhos sobre bons tradutores, que tinham que ser proficientes em inglês e também bons escritores em seus próprios idiomas:

Caro Sr. Saura, [...] também lhe escrevo porque espero que possa me ajudar a resolver um problema relacionado à versão espanhola do filme no qual estou trabalhando agora. O filme se intitula Laranja Mecânica e é baseado no romance de Anthony Burgess. Estou na fase final de edição e o filme será lançado, em sua versão em inglês, no final do ano. A dublagem estrangeira em francês, alemão, italiano e espanhol será realizada entre dezembro e janeiro. Eu nunca tive sucesso com a pós-sincronização nos idiomas de nenhum dos meus filmes. Na melhor das hipóteses, os trabalhos que foram feitos não arruinaram o filme. Na pior das hipóteses, eles arruinaram o filme. Fiquei tão impressionado com o trabalho que você fez no Peppermint Frappe que ficaria extremamente grato se você considerasse supervisionar a dublagem do meu filme para o espanhol. Compreendo que esta não é uma proposta muito empolgante e que normalmente não é o tipo de trabalho que você faria, mas espero que você me perdoe se eu pedir de qualquer forma. Se você se opuser totalmente a essa ideia, em princípio, ou se sua agenda não permitir, eu gostaria de saber se você poderia recomendar alguém que ache que seria bom o suficiente e cujo trabalho não se limitaria exclusivamente a ser um diretor de versões estrangeiras dubladas. Eu também apreciaria qualquer sugestão que você possa ter em relação a tradutores que sejam bons escritores em língua espanhola e que também sejam fluentes em inglês ${ }^{10}$.

Na mesma época, Kubrick entrou em contato com François Truffaut com um pedido semelhante, pedindo conselhos sobre diretores e tradutores para dublagem na França ${ }^{11}$. Truffaut respondeu dizendo que concordava com Kubrick que as versões francesas dos filmes em inglês "deveriam ser feitas com mais cuidado" e recomendou Maurice Dorléac como possível candidato para dirigir a versão dublada de Laranja Mecânica e Maurice Kahane como competente tradutor e escritor. Truffaut também

\footnotetext{
10 Carta a Carlos Saura, 23 de agosto de 1971.

${ }^{11}$ Carta de François Truffaut, 23 de setembro de 1971 (SK 13/8/5/14/1).
} 
aconselhou Kubrick a dar atenção especial à tradução do título, já que a estratégia de legendas em inglês se mostrou até agora bastante malsucedida na França ${ }^{12}$. No mesmo ano, e utilizando uma abordagem semelhante, Kubrick também entrou em contato com Federico Fellini para obter conselhos sobre um bom diretor de dublagem. Fellini recomendou Mario Maldesi, um especialista em pós-sincronização de longasmetragens que tinha trabalhado com Luchino Visconti, Vittorio De Sica e o próprio Fellini, dentre outros (MALDESI, In: ROTA, 1999). Curiosamente, vários anos depois, Fellini entrou em contato com Kubrick com um pedido semelhante. De acordo com Mike Hodges, “Fellini ligou para Stanley Kubrick e disse que sempre passou por momentos ruins ao dublar seus filmes para o inglês. Os resultados nunca lhe agradaram. Stanley recomendou que ele conseguisse um diretor com boa reputação para fazer a dublagem. Foi o que ele fez em cada país onde seus filmes foram lançados" (In: ADAMS, 2001, p. 53-54) ${ }^{13}$.

Foi exatamente isso que aconteceu com a versão brasileira de O Iluminado, que teve o diretor Nelson Pereira dos Santos, cujos filmes Kubrick "admirava muito", encarregado da direção de dublagem (McAVOY, 2015, p. 302). De forma muito semelhante, ele selecionou pessoalmente Edgar Reitz para dirigir a dublagem alemã de De olhos bem fechados. Reitz, que praticamente não tinha experiência na realização de versões em língua estrangeira, lembrou que "Kubrick já tinha visto Heimat: Crônicas

\footnotetext{
${ }^{12}$ Anos mais tarde, Kubrick entrou em contanto com Bertrand Tavernier para que ele supervisionasse a dublagem para língua francesa de O Iluminado e Laranja Mecânica, mas Tavernier se recusou (RASPIENGEAS, 2001, p. 37).

${ }^{13}$ A seguinte carta é bastante ilustrativa em relação à importância cinematográfica que autores como Fellini atribuem à dublagem:

Caro Sr. Kubrick, perdoe-me por lhe distrair de seu trabalho com um pedido de conselho, mas eu não sei a quem recorrer. É o seguinte: eu tenho que dublar meu último filme (E la nave va) para o inglês. A maior parte do filme foi filmada em inglês com atores britânicos, mas eu realmente não posso me responsabilizar por cuidar da versão final em uma língua que eu conheço superficialmente. Você poderia indicar-me alguém que pudesse se encarregar da dublagem do meu filme, da escolha do escritor para a tradução, da adaptação dos movimentos labiais das falas em italiano, da escolha das vozes e da direção dos atores? Dito isso, conhece alguém que disponha de tempo e meios para fazer esse trabalho de forma decente? (TORNABUONI, 1995, p. 97).
} 
de uma nostalgia. Em 1984, o filme foi exibido em um cinema londrino e recebeu muitos elogios. Kubrick gostou muito e entrou em contato comigo. Assim: ‘Oi, aqui é Stanley Kubrick?"”. (REITZ, 2004, p. 244). Segundo Reitz, "Stanley Kubrick queria que os diretores que ele mais reverenciava supervisionassem a dublagem de De olhos bem fechados para os países mais importantes da Europa. Para a França, ele escolheu Patrice Chéreau; para a Espanha, Carlos Saura; para a Itália, Bernardo Bertolucci" (p. 244). As palavras de Reitz parecem confirmar que a regra que Kubrick seguiu com versões em idiomas estrangeiros foi contratar pessoas externas ao mundo altamente profissionalizado da dublagem.

O espírito com o qual os diretores renomados abordaram a dublagem de um filme de Kubrick torna-se aparente nas palavras de Carlos Saura, que escreveu:

Quando Stanley Kubrick sugeriu que eu dirigisse a dublagem espanhola de Barry Lyndon, eu tinha sérias dúvidas [...]. A razão fundamental dessas dúvidas era a crença de que a dublagem é sempre uma traição ao trabalho original. Mas quando eu vi Barry Lyndon, a maioria dessas dúvidas esvaiu-se. Encontrei um argumento para aceitar a oferta de Stanley Kubrick. Eu disse a mim mesmo: a imagem é linda, é magnífica [...] alguém tem que fazer a dublagem, então por que não eu? ${ }^{14}$

\subsection{A busca por bons tradutores}

Kubrick supervisionava todos os aspectos do processo de dublagem, incluindo a seleção dos tradutores. A correspondência armazenada em seu arquivo retrata a importância que ele atribuía à tradução, o que se torna evidente na energia que investia na busca por bons tradutores. Geralmente, "os tradutores são selecionados pelo estúdio de dublagem, que é responsável, após a aprovação de seu cliente, por todo o processo, desde a tradução até a revisão e gravação final" (ZABALBEASCOA; IZARD;

\footnotetext{
${ }^{14}$ Material datilografado em inglês que acompanha o texto original em espanhol (SK/14/5/3/7). 
SANTAMARIA, 2001, p. 107). Esse dificilmente era o caso de Kubrick. Para a versão japonesa dublada de Nascido para matar, por exemplo, ele rejeitou a tradução realizada por Toda Natsuko, "a superestrela do mundo cinematográfico japonês", que havia tentado diluir a obscenidade dos diálogos, e pediu à Twentieth Century Fox para recrutar "alguém que conhecesse o cinema intimamente como produtor e também falasse inglês fluentemente" (NORNES, 2007, p. 216-217). A escolha recaiu sobre Harada Masato, um diretor de cinema que tinha experiência com traduções e havia supervisionado outros projetos de dublagem. Como observa Lachat Leal (2012, p. 9):

[...] é revelador que, ao contrário da tradução literária, na qual um tradutor geralmente se especializa em um determinado autor, tal especialização tende a ser a exceção na tradução audiovisual. A única exceção que conhecemos é Vicente Molina Foix, especificamente selecionado pelo diretor de cinema Stanley Kubrick, que era bem conhecido por seu perfeccionismo e valorizava tanto a dublagem de seus filmes que interveio pessoalmente no processo de seleção de diretores, atores e tradutores para dublagem.

Vicente Molina Foix explica que Kubrick usufruiu do raro privilégio de ter a palavra final, não apenas sobre a forma do filme em termos artísticos, mas também sobre quem deveria fazer a tradução dos diálogos, sendo sua preferência por profissionais externos à indústria da tradução audiovisual:

[...] entre 1971 e 1975, o ano de produção de seu próximo filme, Barry Lyndon, Kubrick recebeu um dos muitos privilégios que caracterizariam sua carreira como um perfeccionista exigente, tolerado pelos magnatas de Hollywood graças ao imenso lucro que proporcionava para as bilheterias. O privilégio em questão era o de impor à Warner Brothers que seus filmes fossem traduzidos por escritores ou tradutores literários para cada um dos idiomas em que seriam distribuídos e, em países onde a dublagem era indispensável, que a direção fosse confiada a um cineasta de prestígio que o próprio Kubrick selecionaria. (MOLINA FOIX, 2005, minha tradução) 
Vicente Molina Foix foi contratado para revisar a tradução espanhola dos diálogos de Laranja Mecânica, que Saura considerou inadequada:

Kubrick admirava Saura [...] e, em 1975, ofereceu a ele a direção da dublagem espanhola de Barry Lyndon. Nessa ocasião, Saura aceitou a tradução dos diálogos que lhe havia sido fornecida, mas quando começou a trabalhar na dublagem de Laranja Mecânica, seguindo o conselho de Geraldine Chaplin, ele rejeitou a tradução, que aparentemente havia sido realizada em algum escritório dos estúdios americanos. (MOLINA FOIX, 2005, minha tradução)

Em carta datada de 23 de novembro de 1977, Jan Harlan escreveu a Frank Pierce, da Warner Bros de Londres, que "vários espectadores espanhóis que poderiam avaliar o material disseram que o roteiro da dublagem para o espanhol feito por Lopez Rubio, embora estivesse extremamente bem escrito, era um pouco acadêmico e não refletia o humor do filme" e expressaram o desejo de Kubrick de nomear Molina Foix para revisá-lo. ${ }^{15}$

\subsection{Controle das traduções}

Kubrick desprenderia grandes esforços para garantir que seus filmes fossem bem traduzidos. Assim, é ainda mais revelador que numerosas cópias das traduções que foram feitas em todos os idiomas, fossem para fins de dublagem ou legendagem, estejam disponíveis no Arquivo Stanley Kubrick, juntamente com outros documentos inéditos no que tange à distribuição dos filmes de Kubrick nos mercados de idiomas estrangeiros. Com idiomas como o japonês, o procedimento era ter um "roteiro de quatro colunas, em paralelo, realizado por um segundo tradutor independente", exibindo a tradução japonesa proposta, uma transliteração para romaji, uma tradução palavra por palavra e uma retrotradução para o inglês (NORNES, 2007, p. 216-217). A

\footnotetext{
${ }^{15}$ Cópia em carbono, SK/13/4/14/3/11.
} 
tradução era então anotada e as revisões eram enviadas de volta ao tradutor. As retrotraduções também eram encomendadas para os idiomas europeus. Por exemplo, um dos arquivos contém uma retrotradução para o inglês da tradução espanhola de Tony Navarro para a versão dublada de Laranja Mecânica a ser distribuída na América Latina $^{16}$.

A cada passo, Kubrick foi consultado na medida em que a produção da versão estrangeira avançava e especialistas em idiomas eram consultados para todos os idiomas envolvidos. Por exemplo, o estudioso de cinema Jean-Loup Bourger atuou como consultor para a versão francesa de Barry Lyndon (SK/14/5/7/61), ao passo que Donald Keene, um eminente estudioso e tradutor de literatura japonesa, foi consultado para revisar as legendas em japonês de Dr. Fantástico ${ }^{17}$.

\subsection{Seleção das vozes}

Como diretor de cinema, "Kubrick cuidava tanto dos sons das palavras faladas quanto das próprias palavras" (McQUISTON, 2013, p. 11). E ele fez o mesmo com as versões dubladas, tendo um papel ativo na seleção do elenco de vozes e prestando muita atenção tanto à qualidade vocal quanto à sua reprodução. Os dados de estudos contemporâneos, bem como as evidências arquivísticas, sugerem que Kubrick selecionou vozes de dubladores que muito combinavam com as originais. Por exemplo, foi o próprio diretor que escolheu a atriz espanhola Verónica Forqué para dublar Shelley Duvall em O Iluminado. Forqué lembra que ela foi selecionada não tanto em virtude de suas habilidades como atriz, mas graças à sua voz:

\footnotetext{
$16 \mathrm{O}$ material datilografado se encontra nas pastas pertencentes à distribuição na América Latina. $(\mathrm{SK} / 13 / 4 / 14 / 3 / 11)$.

17 Keene foi professor na Universidade de Columbia e autor de vários livros sobre cultura e literatura japonesa, incluindo uma antologia de literatura japonesa intitulada Anthology of Japanese Literature: from the earliest era to the mid-nineteenth century (1956). Ele traduziu tanto trabalhos clássicos quanto modernos. A correspondência entre Keene e o assistente de Kubrick, Ray Lovejoy, está armazenada nos arquivos do Arquivo Stanley Kubrick sobre o filme Dr. Fantástico.
} 
Ele não me escolheu porque gostava de mim como atriz, mas porque minha voz era muito parecida com a de Shelley Duvall. O diretor de dublagem, Carlos Saura, enviou as vozes de várias atrizes e Kubrick escolheu a minha. Quando entrei no estúdio de dublagem e eles me deram a primeira tomada, senti uma enorme responsabilidade, mas acho que Kubrick ficou muito feliz com o resultado final. (In: ARIS, 2011, minha tradução)

Descrita como "uma das mais envolventes presenças cômicas no cinema espanhol durante os anos 1980 e início dos anos 1990", Verónica Forqué era conhecida por sua voz peculiar e "animada" (MIRA, 2010, p. 135). De acordo com Mira, esse foi um grande erro na seleção de talentos de vozes, já que "sua voz inconfundível era reconhecível demais" (MIRA, 2010), contribuindo assim para o que é considerado "um dos casos mais desastrosos de dublagem na Espanha" (WHITTAKER, 2012, p. 303). Molina Foix (1999) afirmou claramente que Kubrick foi responsável pelas seleções que foram feitas para a versão espanhola dublada:

[...] alguns cinéfilos irritados que sabiam de minha conexão (com Kubrick) me criticaram (e criticaram indiretamente Saura, o diretor de dublagem) pelas vozes dos protagonistas de O Iluminado que eles acharam bizarras. Sempre digo que essas foram as vozes que, dentre as de muitos outros atores de cinema ou teatro (não de dubladores), foram selecionadas pelo próprio Kubrick, de Londres, nesse caso Verónica Forqué e Joaquín Hinojosa, cujas vozes - tão raras e distantes de clichês - ele sentiu serem perfeitas para transmitir o inglês falado por Shelley Duvall e Jack Nicholson. (minha tradução)

Ele também aponta para a insistência de Kubrick em ter atores de cinema ou teatro em vez de dubladores pertencentes à indústria de dublagem, um relato também feito por outros profissionais envolvidos na dublagem em língua estrangeira dos seus filmes. Michel Deville lembrou, por exemplo, que o diretor rejeitou as vozes originalmente selecionadas para o personagem interpretado por Jack Nicholson na versão francesa de O Iluminado, incluindo a voz oficial de Nicholson na França. Ele 
queria um ator "louco e talentoso como Trintignant" 18 , que foi de fato roteirizado para o papel. Segundo Trintignant, ele foi selecionado somente com base em testes de voz, pois Kubrick não sabia quem ele realmente era. ${ }^{19}$

Segundo Carlos Saura, uma das principais questões com relação à versão dublada de Barry Lyndon era encontrar os dubladores certos. Kubrick sempre fez questão de trabalhar "com os melhores atores": [...] "Ele verificava cada voz e estava interessado em cada detalhe. Sua preocupação com seu trabalho era quase uma obsessão. Acho que era para ser assim, pois ele só me via como intermediário entre suas ideias, seu filme e sua transcrição em espanhol" (Carlos Saura, datilografado, SK/14/5/3/7). Kubrick ficou realmente muito satisfeito com as escolhas que Saura havia feito para Barry Lyndon, como evidenciado por um texto datilografado com notas aparentemente feitas na forma de anotações para o uso do diretor espanhol ${ }^{20}$ :

SK considera, cumprimenta e agradece Saura e elogia as excelentes escolhas. [...] O Sr. K é totalmente dependente do julgamento de Saura em relação aos atores que ele aprovou; pouquíssimos têm vozes correspondentes e o espanhol de SK não é suficientemente bom para dizer se ele tem dúvidas sobre algum dos atores que o SK aceitou com base nos testes ${ }^{21}$.

Curiosamente, mesmo na ausência do diretor de cinema, os mesmos princípios foram seguidos na realização da versão alemã de De olhos bem fechados. Como Edgar Reitz (2004, p. 246-247) lembrou, uma atenção especial foi dedicada a encontrar vozes correspondentes e cada detalhe da performance foi minuciosamente averiguado. "Nosso trabalho em De olhos bem fechados foi uma exceção", disse Reitz em uma

\footnotetext{
${ }^{18}$ Entrevista incluída nos conteúdos extras da edição francesa de De olhos bem fechados (tradução minha).

19 "Eu tive que passar por alguns testes de voz e Kubrick me escolheu pelo som da minha voz, sem saber quem eu era, relatou Jean-Louis. Eu nunca o conheci, mas Michel Deville, que supervisionou a dublagem, falava com ele todas as noites pelo telefone" (DURANT, 2017, p. 153, minha tradução).

${ }^{20}$ A soletração original é mantida sem alterações em todo o material de arquivo citado.

${ }^{21}$ Carta datilografa, s. d., SK/14/5/22.
} 
entrevista (2004, p. 247), pois "eu tentei fazer as coisas de maneira diferente da dublagem comum" (p. 245).

\subsection{Mixagem}

Uma das maneiras através das quais Kubrick conseguiu manter o controle sonoro de seus filmes traduzidos foi realizando as gravações localmente, mas também mixando-as em Londres, como ele disse a Danièle Heymann. Mario Maldesi, que supervisionou as versões dubladas italianas dos principais filmes de Kubrick, contou que inicialmente rejeitou a oferta de dirigir a versão italiana de Laranja Mecânica, porque Kubrick lhe pediu que se limitasse a entregar as gravações em masters e Maldesi se opôs à ideia de não permanecer no controle de todo o processo:

No início eu recusei a oferta porque me pediram para não fazer a mixagem e entregar apenas as gravações em master. Meu trabalho termina quando a mixagem é feita e eu senti que não podia ser excluído disso. Kubrick escreveu uma carta para a Warner da Itália que me foi entregue, na qual ele tentou me fazer mudar de ideia: ela foi datilografada, ao contrário daquelas que eu recebi ao concluir o trabalho para cada filme. Kubrick disse que entendia perfeitamente minhas razões e ficou satisfeito em saber o quanto eu me importava com meu trabalho; no entanto, ele estava acostumado a lidar pessoalmente com a mixagem, não tinha nada a ver comigo, e ele me garantiu, brincando, que não iria arruinar meu trabalho. Por isso, eu sempre enviava as fitas italianas para Londres, onde elas seriam mixadas por Kubrick. (In: ROTA, 1999, minha tradução)

Ao intervir na última etapa do processo de dublagem, Kubrick conseguiu manter o controle e, por fim, deixar sua marca no resultado final. Trabalhar em um filme desse diretor era, no entanto, uma empreitada colaborativa, na qual o trabalho dos diretores de dublagem era supervisionado de perto por ele mesmo, que tinha a última palavra sobre os dubladores e gerenciava pessoalmente a fase final da mixagem do som, dando, assim, forma às versões finais dubladas. Ao supervisionar todos os 
aspectos do processo de dublagem, incluindo pormenores linguísticos nas traduções, Kubrick conferia um status especial às versões em língua estrangeira de seus filmes. Penso que essas devam ser consideradas como versões autorizadas, para as quais foi imposta uma marca autoral extraordinariamente inequívoca.

\subsection{Escolhas autorais}

As escolhas autorais envolviam o que parecem ser inconsistências aparentes, como no caso em que Peter Sellers foi dublado pelo mesmo dublador em Lolita, no qual ele interpreta um personagem (Clare Quilty) fazendo-se passar por outra pessoa (Dr. Zempf), e que foi dublado por três dubladores diferentes em Dr. Fantástico, no qual ele interpretou três papéis diferentes e independentes. Uma carta de Erich Müller, diretor geral da filial alemã da Columbia Pictures, revela que houve negociações sobre a forma como a versão alemã dublada seria interpretada. Müller escreveu:

notamos que você prefere que Peter Sellers seja dublado por três dubladores alemães diferentes. Nossos dubladores, assim como nós, são da opinião unânime de que Peter Sellers deveria ser dublado por um dublador, pois esse método garantiria a uniformidade artística, ao passo que uma dublagem por três vozes diferentes reduziria a imagem artística desse filme ${ }^{22}$.

É importante lembrar que a Columbia Pictures insistiu que Peter Sellers fosse selecionado para pelo menos quatro papéis principais. Sellers acabou interpretando três dos quatro papéis escritos para ele, o que consagrou o filme "mais para o reino da sátira" (HUGHES, 2000, p. 111). Cada um dos três personagens retratados por Sellers têm sotaques e personalidades completamente diferentes: Mandrake, que é Capitão de Grupo da Força Aérea Real Britânica, fala com sotaque britânico; o Presidente Mauffley fala com sotaque do centro-oeste americano; enquanto o discurso do Dr.

\footnotetext{
${ }^{22}$ Carta de Erich Müller a Stanley Kubrick datada em 26 de fevereiro de 1964 (SK/11/4/5, Box 2).
} 
Fantástico é caracterizado por um forte sotaque alemão. Seguindo as instruções de Kubrick, tanto na versão italiana quanto na espanhola, Peter Sellers foi dublado por três dubladores diferentes (Cap. Lionel Mandrake: Giuseppe Rinaldi/Julio Lucena; Pres. Merkin Muffley: Carlo Romano/Francisco Colmenero; Dr. Fantástico: Oreste Lionello/Fernando Rivas Salazar). Curiosamente, a versão francesa de Lolita seguiu uma abordagem diferente ao ter Sellers dublado por dois dubladores diferentes (Michel Roux como Clare Quilty e Roger Carel como Dr. Zempf), enquanto o mesmo dublador foi usado para todos os três papéis em Dr. Fantástico.

\section{Kubrick e a dublagem}

Segundo Mario Maldesi, Kubrick “gostava da dublagem e a considerava um evento criativo de grande importância" (MALDESI, 2007). Kubrick não era novato em usar a dublagem para compensar performances originais que ele não considerava propriamente bem-sucedidas. Por exemplo, ele dirigiu Anthony Hopkins na dublagem de Lawrence Olivier, na cena "ostras e caracóis" para a versão remasterizada de Spartacus (1991) e o fez por fax. Na versão lançada em 1960, Kubrick havia sido forçado a apagar a cena em que Crassus (Olivier) tenta seduzir Antoninus (Curtis) e revela sua homossexualidade perguntando se prefere comer ostras ou caracóis. Como Kubrick explicou a Hopkins, a performance de Olivier "teve um final problemático e remoto [...]. Não havia nada de sugestivo ou exagerado sobre Larry" (In: PHILLIPS e HILL, 2002, p. 149), assim ele pediu a Hopkins que recuperasse a intenção original da cena. De maneira semelhante, ele pedia frequentemente a Maldesi que fizesse pequenos ajustes nas performances dos atores originais:

Kubrick muitas vezes nos pedia para fazer pequenas mudanças na versão dublada, principalmente correções relativas à performance dos atores originais. Lembro-me de um pedido que ele nos fez sobre Ryan O'Neal, que aparentemente não tinha conseguido interpretar a intenção original de Kubrick. [...] Como o elenco de voz incluía 
Giancarlo Giannini, um ator muito melhor que Ryan O'Neal, Kubrick me pediu para recuperar a intenção que a versão em inglês não havia transmitido. Ele estava entusiasmado com a versão dublada, que ele pessoalmente mixou. Ele sentiu uma mistura de espanto e satisfação, como se observasse dois gêmeos lindos, com a mesma aparência e ainda assim diferentes, e via cada um andando com seus próprios pés, com vida própria, embora semelhantes entre si. (In: ULIVIERI, 2002, minha tradução)

A visão oposta é afirmada pelo colaborador de longa data de Kubrick, Jan Harlan. Em sua opinião, "Kubrick não gostava de dublagem, embora nós nos esforçássemos muito, mas muito mesmo para acertar. Mas é algo que não se consegue acertar". É sempre falho. Lembro-me dele dizendo que os alemães se vingaram por terem perdido a guerra ao dublarem seus filmes"23. Segundo Harlan, Kubrick considerou o advento do formato DVD como um meio de finalmente "nos livrarmos das faixas horrivelmente dubladas e voltarmos à versão original" (In: ULIVIERI, 2002).

Entretanto, ao olhar o material de arquivo em nossa posse e os testemunhos dos profissionais de dublagem com quem ele trabalhou, logo fica evidente que o diretor fez mais do que apenas "tentar acertar". Ao contrário, ele não apenas optou por envolver-se no processo de dublagem, mas parecia considerar a dublagem como uma segunda chance de levar suas obras à perfeição. Por ocasião da edição de 1997 do Festival de Veneza, onde foi realizada uma retrospectiva de seus filmes, ele insistiu que seus filmes fossem exibidos em suas versões dubladas em italiano em vez de em inglês com legendas em italiano. De acordo com o diretor do Festival de Veneza, Felice Laudadio, Kubrick afirmou: “Eu faço filmes com imagens [...] e tenho supervisionado pessoalmente as versões italianas dos meus filmes. Quero que os espectadores vejam as imagens e escutem os diálogos sem se distrair com as legendas"24. Essa anedota

\footnotetext{
${ }^{23}$ http://www.dvdtalk.com/janharlaninterview.html.

24 "Kubrick era um gênio de mau temperamento, meticuloso ao ponto de soar arrogante. Por exemplo, na ocasião do lançamento da $54^{a}$ edição do Festival de Cinema de Veneza, eu organizei uma
} 
parece sugerir que Kubrick entendia a dublagem como um meio de criar uma experiência imersiva do filme. Como afirma Ascheid (1997, p. 33):

[...] a versão dublada e a original estão muito mais estreitamente ligadas em termos de seu efeito sobre o público doméstico, análogo ao de duas versões de múltiplas línguas da mesma narrativa, enquanto a versão legendada contém uma série de elementos reflexivos que possuem um potencial muito maior para quebrar a identificação cinematográfica, a suspensão da descrença e uma experiência contínua de prazer ininterrupto 25 .

A abordagem de Kubrick ao utilizar a dublagem deve ser entendida, penso eu, à luz de sua estética. Como aponta Michel Ciment, "a intenção de Kubrick é a de concentrar a atenção do espectador no filme, já que a visão é o único ato puro, e todo o restante mais empobrecido, falsificado, atenuado" (2001, p. 233). Esse, a meu ver, é precisamente o motivo que sustenta sua preocupação e envolvimento nas versões dubladas.

\section{Conclusões}

Neste trabalho, foi introduzida a noção de "dublagem de autor" para descrever a dublagem de longas-metragens diretamente supervisionada pelo diretor de cinema, como foi o caso da maioria dos filmes de Stanley Kubrick. Nosso conhecimento do envolvimento real dos diretores de cinema na tradução de seus filmes ainda é muito limitado, mas como tentei demonstrar analisando o caso Stanley Kubrick, o uso de

retrospectiva de seus filmes e ele insistiu que seus filmes fossem exibidos nas versões dubladas em italiano, em vez dos originais legendados. Mesmo assim, sua decisão foi tão paradoxal quanto indiscutível: Eu faço filme com imagens, ele escreveu, e eu supervisionei pessoalmente as versões em italiano dos meus filmes. Eu quero que os espectadores vejam as imagens e escutem os diálogos, que são estreitamente interligados com as imagens, sem serem distraídos pelas legendas. Portanto, por favor, exiba os meus filmes em italiano, caso contrário, eu não concederei aprovação para a retrospectiva" (LAUDADIO, 1999, tradução minha).

${ }^{25}$ Ver Di Giovanni e Romero Fresco no volume Reassessing Dubbing: Historical approaches and current trends (2019). 
métodos e recursos arquivísticos podem ajudar a esclarecer esse aspecto ainda em grande parte desconhecido da distribuição cinematográfica.

Kubrick considerou a tradução e a dublagem de filmes como partes do viés artístico do processo de produção. Por essa mesma razão, ele trabalhou muito para garantir que a recepção de seus filmes traduzidos não fosse afetada pela transferência a outro idioma e assumiu um papel ativo em todo o processo, muitas vezes deixando uma marca autoral inconfundível no produto final. O material pertencente ao Arquivo Stanley Kubrick é um testemunho do trabalho que envolveu tudo isso - desde a contratação de bons tradutores e diretores de dublagem, de preferência externos à indústria de dublagem, até o trabalho em estreita colaboração com eles, desde a seleção dos dubladores, passando pelo cuidado de todos os detalhes da distribuição, incluindo a arte e o material publicitário, até a verificação da qualidade dos projetores.

As evidências arquivísticas parecem indicar que, para Kubrick, estar no controle sonoro audível era tão importante quanto controlar as palavras traduzidas. Como ele declarou em sua entrevista concedida em 1987 para Heymann, ele considerava a dublagem como sendo, essencialmente, uma refilmagem do filme. Ao tecer a subversão das normas industriais e o controle autoral no próprio tecido da dublagem, ele forneceu um exemplo vivo dos benefícios que uma abordagem autoral da dublagem e da tradução em geral podem ter sobre a qualidade e a integridade artística do cinema de autor.

\section{Referências do texto traduzido}

ADAMS, M. Mike Hodges: The Pocket Essential Guide. Summersdale Publishers LTD - ROW, 2001.

ARIAS, J. Cuando Kubrick me eligió para doblar 'El resplandor', me dio un subidón [When Kubrick chose me to dub 'The Shining']. 4 de novembro, 2011. http://www.granadahoy.com/ocio/Kubrick-eligio-doblar-resplandorsubidon 0 530347607.html (Acesso em: 5 nov. 2017). 
ASCHEID, A. Speaking Tongues: Voice Dubbing in the Cinema as Cultural Ventriloquism. The Velvet Light Trap, no. 40, p. 33-41, 1997.

BETZ, M. Beyond the Subtitle: Remapping European Art Cinema. Minneapolis/London: University of Minnesota Press, 2009.

BOGDANOVICH, P. What They Say About Stanley Kubrick. The New York Times, 4 de julho, 1999. http://www.nytimes.com/1999/07/04/magazine/what-they-say-aboutstanley-kubrick.html (Acesso em: 5 nov. 2017).

CHIARO, D. Not in front of the children? An analysis of sex on screen in Italy. REMAEL, A; NEVES, J. A Tool for Social Integration? Audiovisual Translation from Different Angles. Linguistica Antverpiensia. New Series, no. 6, p. 255-276, 2007.

CIMENT, M. Kubrick. The Definitive Edition. Tradução do francês de Gilbert Adair. New York: Faber and Faber, 2001.

DÍAZ CINTAS, J. Striving for quality in subtitling: the role of a good dialogue list. In: GAMBIER, Y.; GOTTLIEB, H. (Multi)Media Translation: Concepts, Practices and Research, John Benjamins: Philadelphia, 2001. p. 199-211. DOI https://doi.org/10.1075/btl.34.25dia

DURANT, P. Jean-Louis Trintignant. Paris: Editions Générales First, 2017.

HEYMANN, D. Stanley Kubrick's Vietnam. In: CASTLE, Al. (org.). The Stanley Kubrick Archives, p. 476-479, 2005. Hong Kong: Taschen. [originalmente publicado como Le Vietnam de Stanley Kubrick: Un entretien avec le réalisteur de Full Metal Jacket, Le Monde, 20 de outubro de 1987.]

HILL, R.; PHILLIPS, G. (org.). Encyclopedia of Stanley Kubrick: From Day of the Fight to Eyes Wide Shut. New York: Facts on File, 2002.

HODSDON, B. The Elusive Auteur: The Question of Film Authorship Throughout the Age of Cinema. Jefferson: McFarland, 2017.

HOOTON, C. Read the alternative phrases to 'All work and no play makes Jack a dull boy' Stanley Kubrick considered for The Shining. The Independent, junho, 2015. http://www.independent.co.uk/arts-entertainment/films/news/read-the-alternativephrases-to-all-workand-no-play-makes-jack-a-dull-boy-stanley-kubrick10312563.html (Acesso em: 3 nov. 2017). 
HUGHES, D. The Complete Kubrick. London: Virgin, 2000.

LACHAT LEAL, C. Visual perception and audiovisual translation: directed vision. MonTI 4trans, p. 1-12, 2012.

LAUDADIO, F. Quando m'impose di dare i suoi film in italiano. [When he forced me to exhibit his films in Italian]. L'Unità, 8 de março de 1999.

MALDESI, M. Intervista a Mario Maldesi. [Interview with Mario Maldesi] aSinc. Rivista in rete di critica del doppiaggio, 2007. http://www.asinc.it/as 01 033.asp (Acesso em: 3 nov. 2017).

McAVOY, C. Creating The Shining: Looking Beyond the Myths. In: LJUJIĆ, T.; KRÄMER, P.; DANIELS, R. (org.). Stanley Kubrick: New perspectives. London: Black Dog Publishing, 2015. p. 282-307.

McDOUGAL, S. Stanley Kubrick's A Clockwork Orange. Cambridge: Cambridge University Press, 2003. DOI https://doi.org/10.1017/CBO9780511615306

McQUISTON, K. We'll Meet Again: Musical Design in the Films of Stanley Kubrick. Oxford: Oxford University Press, 2013. DOI

https://doi.org/10.1093/acprof:oso/9780199767656.001.0001

MILON, C.; RENOUARD, J.-P. R. Les yeux grand fermés: à propos du doublage de Eyes Wide Shut- entretien avec Pascale Ferran. [Eyes Wide Shut: On the dubbing of Eyes Wide Shut - interview with Pascale Ferran]. VACARME, no. 10, 1999. http://www.vacarme. org/article874.html (Acesso em: 5 nov. 2017). DOI https://doi.org/10.3917/vaca.010.0042

MIRA, A. The A to Z of Spanish Cinema. Lanham, MD: Scarecrow Press, 2010.

MOLINA FOIX, V. An Interview with Stanley Kubrick. In: CASTLE, A. (org.). The Stanley Kubrick Archives. Hong Kong: Taschen, p. 460-464, 1980. [originalmente publicado [El Pais- Artes, 20 de dezembro de 1980.]

MOLINA FOIX, V. El artista maniático. [The obsessive artist]. El País, 8 de março de 1999. https://elpais.com/diario/1999/03/08/cultura/920847607 850215.html

MOLINA FOIX, V. El Director Exquisito. [The exquisite director]. El País, 6 de março de 2005. https://elpais.com/diario/2005/03/06/eps/1110094011 850215.html (Acesso em: 5 nov. 2017). 
NORNES, A. M. Cinema Babel - Translating Global Cinema. Minneapolis: University of Minnesota Press, 2007.

O'SULLIVAN, C. Images Translating Images: “Dubbing” Text on Screen. L'Écran traduit, no. 2, p. 123-142, 2013.

PÉREZ-GONZÁLEZ, L. Audiovisual Translation: Theories, Methods and Issues. New York: Routledge, 2014.

RASPIENGEAS, J.-C. Bertrand Tavernier. Paris: Flammarion, 2001.

REITZ, E. Our Work Was an Exception: Directing the Dubbing of Eyes Wide Shut. Interview with Edgar Reitz. In: REICHMANN, H.-P.; FLAGGE, I. (org.) Stanley Kubrick (Deutsches Filmmuseum Frankfurt am Main, Deutsches Architekturmuseum: Frankfurt am Main). Kinematograph, no. 20, p. 244-249, 2004.

RENOUARD, J.-P. La fin de Babel. [The end of Babel]. VACARME, no. 10, p. 47, 1999. http:// www.vacarme.org/article873.html (Acesso em: 3 nov. 2017). DOI https://doi.org/10.3917/vaca.010.0047

RIOU, Alain. Une étincelle inimitable! [An inimitable spark!]. Le Nouvel observateur 1196 (9-15 de outubro), p. 52-54, 1987.

ROTA, A. Le voci per Stanley? Un lavoro bellissimo. [The voices for Stanley? A $\begin{array}{llllll}\text { beautiful job]. La Repubblica 1, setembro, } & 1999 .\end{array}$ http://ricerca.repubblica.it/repubblica/archivio/repubblica/1999/09/01/le-voci-perstanley-un-lavoro-bellissimo.html?refresh ce (Acesso em: 3 nov. 2017).

SZARKOWSKA, A. Auteur Description: From the Director's Creative Vision to Audio Description. Journal of Visual Impairment \& Blindness, v. 107, no. 5, p. 383-387, 2013.

TORNABUONI, L. (org.). Federico Fellini. Milano: Rizzoli, 1995.

ULIVIERI, F. Conversazione con Mario Maldesi [Conversation with Mario Maldesi]. Archivio Kubrick, 2002. http://www.archiviokubrick.it/testimonianze/persone/maldesi.html (Acesso em: 3 nov. 2017). 
WEINRAUB, B. Kubrick Tells What Makes 'Clockwork Orange' Tick. The New York Times, janeiro, no. 26, 1972. http://www.nytimes.com/1972/01/04/archives/kubricktellswhat-makes-clockwork-orange-tick.html (Acesso em: 3 nov. 2017).

WHITMAN-LINSEN, C. Through the Dubbing Glass. The Synchronization of American Motion Pictures into German, French and Spanish. Frankfurt am Main: Peter Lang, 1992.

WHITTAKER, T. Locating "la voz": The space and sound of Spanish dubbing. Journal of Spanish Cultural Studies, v. 13, no. 3, p. 292-305, 2012.

ZABALBEASCOA, P.; IZARD, N.; SANTAMARIA, L. Disentangling Audiovisual Translation. In: GAMBIER, Yves; GOTTLIEB, Henrik. (org.). (Multi) Media Translation: Concepts, Practices, and Research, 2001, p. 101-112. Amsterdam and New York: Benjamins. DOI https://doi.org/10.1075/btl.34.13zab

\section{Filmografia}

2001: A Space Odyssey (2001: Uma odisseia no espaço). Stanley Kubrick. UK/USA. 1968. Barry Lyndon. Stanley Kubrick. UK/USA. 1975.

Dr. Strangelove (Dr. Fantástico). Stanley Kubrick. UK/USA. 1964.

Eyes Wide Shut (De olhos bem fechados). Stanley Kubrick. UK/USA. 1999.

Full Metal Jacket (Nascido para matar). Stanley Kubrick. USA/UK. 1987.

Lolita. Stanley Kubrick. UK/USA. 1962.

The Shining (O Iluminado). Stanley Kubrick. USA/UK. 1980.

Spartacus. Stanley Kubrick. USA. 1960 (Restored edition 1991). 